\section{IMPORTANCE OF TITANIUM AND ITS ALLOYS IN ENGINEERING}

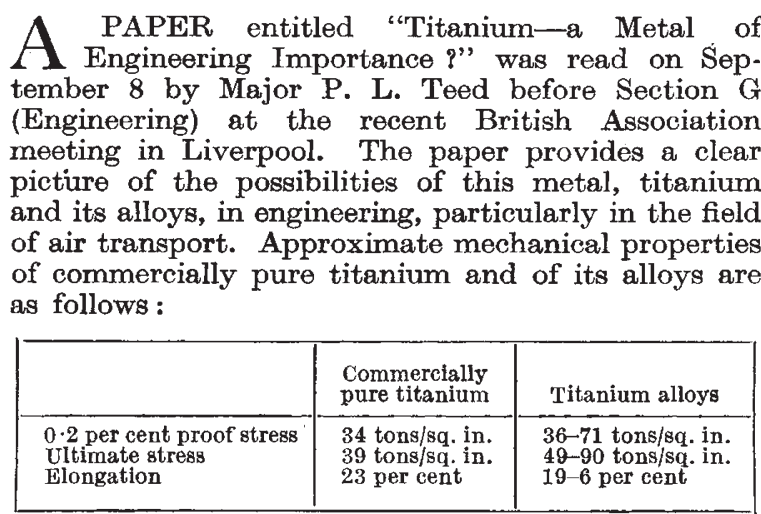

As with alloy steels, the room-temperature notchedbar impact resistance of the titanium alloys tends to decrease with increase in tenacity. A wrought, commercially pure titanium bar may, at room temperature, have a Charpy notch-bar value exceeding $50 \mathrm{ft} .1 \mathrm{~b}$., while that of many of the stronger alloys may not, under similar conditions, absorb as much as $10 \mathrm{ft}$. $\mathrm{lb}$.

As regards fatigue, at room temperature and employing standard test-pieces that are unnotched, the resistance of titanium and its alloys is impressively high-there can be little doubt that on the basis of ten million reversals of stress, this exceeds 50 per cent of the ultimate static tensile stress of the material. With regard to notched specimens, however, a less happy report has to be made. The impression arising from the work which has been done is that the metal and its alloys are much more notch-sensitive than alloy steels of the same static strength. Further, there is some evidence to show that, as the stress concentration factor is increased, the endurance is reduced to a considerably greater extent than would be the case with steels having similar static mechanical properties.

Titanium alloys, like those of other metals, are heat-sensitive. Above $100^{\circ} \mathrm{C}$. and under comparable conditions, they have better specific mechanical properties than the wrought aluminium alloys; but at temperatures in excess of $400^{\circ} \mathrm{C}$. those of several ferrous and non-ferrous alloys are superior to the best of the titanium ones, and above $800^{\circ} \mathrm{C}$. hydrogen, nitrogen, oxygen, steam, carbon monoxide and carbon dioxide react vigorously with the hot metal.

Before leaving the mechanical properties of the metal and of its alloys, one troublesome defect must be mentioned. Both have quite deplorable frictional properties, and the metal is inclined to 'pick up', not only on itself but also on any other on which it is rubbing. It is possible, however, that some type of surface finish may be discovered which will overcome this difficulty.

So far as the chemical properties of the materials are concerned, it is already clear, although further work is required in more than one direction, that titanium and its alloys are resistant to a remarkable degree. Since this applies to sea water, even at temperatures up to those experienced in a steam condenser, titanium is a material of very definite interest to the marine engineer.

At present, though not necessarily for all time, really satisfactory castings cannot be made in titanium or its alloys, since all the materials which have so far been used for the moulds have been found to be attacked in varying degrees by the molten metal. Even should this difficulty be solved, the production of such castings will still prove difficult. The molten metal combines with vigour with so many gases that special melting and casting techniques would appear to be essential.

This intense chemical activity requires that titanium and its alloys should be forged in the temperature-range $880-980^{\circ} \mathrm{C}$., and again, unless the heating is carried out in an inert gas, scale will be formed, which tends to reduce the life of the dies. Some of the two-phase alloys are subject to marked grain growth, necessitating quicker heating and a heavy reduction per heat, while subsequent heat treatment to bring about phase transformations may also be beneficial. The hot extrusion of the materials, given suitable die lubrication, presents little technical difficulty, and one most interesting lubricant suitable for these metals is molten glass. Cold drawing, if the metal is covered with a thin film of scale, presents few difficulties; but if the scale coat is inadequate, pick-up will occur.

The welding of titanium and its alloys must be carried out under conditions which prevent chemical reaction between the hot, or molten, metal and the surrounding atmosphere, and the helium or argon arc becomes ideal. Due, however, to the surface embrittlement which results when the materials are hea ed in air, the whole of the hot metal must be encl ised in an inert atmosphere, inert gas being fed to bith sides of the weld during the operation. With commercially pure titanium and with the single-phase alloys, such modified helium- or argon-are techniques produce extremely good welds, having an ultimate tensile strength and ductility of the same order as that of the basis metal. In the case of the two-phase alloys, however, although the tensile strength of the weld is satisfactory, the ductility is normally disappointing.

The machining of these materials still presents difficulties, and the best tool materials, cutting speeds, lubrication, etc., are still far from being satisfactorily determined. Commercially pure titanium can be deep-drawn to about the same extent as a low-carbon steel, but more frequent annealing is required and lower press-speeds. With the alloys of titanium, greater difficulties are experienced as their tensile strength increases, but a comparatively small increase of temperature, say, to $250-350^{\circ}$ C., will greatly facilitate the more difficult press operations.

The second half of Major Teed's paper was devoted to a detailed consideration of the effect of the sub. stitution of titanium in appropriate aircraft parts. Despite the high cost of the metal, varying from $£ 3 \cdot 5 / \mathrm{lb}$. for hot rolled rods to $£ 5 \cdot 3 / \mathrm{lb}$. for annealed sheet, its high mechanical properties and relatively low density suggest that by such 'titanizing' the disposable load of a machine at present having a basic equipped weight of $70,000 \mathrm{lb}$. could be increased by about 1,550 $\mathrm{lb}$. or, alternatively, that in the design of an aircraft with a given disposable load such uses of titanium would result in a slightly smaller machine with certain ancillary advantages.

In Major Teed's view the question contained in the title of his paper-even at its present price-can be answered in the affirmative. Titanium and its alloys will have applications in mechanical, aeronautical and, possibly, marine engineering, and, as the price falls, the field of utility will surely widen. 